\title{
ANÁLISE DA VIABILIDADE DA CONSTRUÇÃO DE UM ATERRO SANITÁRIO NO MUNICÍPIO DE RANCHARIA (SP) POR MEIO DE ENGENHARIA ECONÔMICA
}

Analysis of the feasibility of the construction of a landfill in the municipality of Rancharia (SP) through economic engineering

Arthur Pereira dos Santos ${ }^{1}$, Elson Mendonça Felici ${ }^{2}$, Marcelo Rodrigo Alves ${ }^{2}$, Felipe Kesrouani Lemos ${ }^{2}$

${ }^{1}$ Universidade Federal de Uberlândia - UFU. ${ }^{2}$ Universidade do Oeste Paulista -
UNOESTE.
E-mail: arthurpdosantos@outlook.com; elson@unoeste.br;
sabino89alves@hotmail.com; felipeklemos@unoeste.br

RESUMO - O presente trabalho objetivou analisar a viabilidade da construção de um aterro sanitário no município de Rancharia - SP, visando atender às normas estabelecidas pela Política Nacional de Resíduos Sólidos (PNRS), reduzir custos com a destinação adequada do lixo, diminuir a poluição ambiental e evitar possíveis penalidades impostas pela Companhia Ambiental do Estado de São Paulo (CETESB). Realizou-se abordagem quantitativa para verificar a viabilidade econômica das alternativas de investimento, com a aplicação de métodos de Engenharia Econômica, como o método do Valor Presente Líquido (VPL). As informações necessárias para a análise, relativas as projeções de geração de resíduos sólidos pelo município de Rancharia, aos custos com a terceirização da destinação adequada do lixo, aos custos com as etapas do ciclo de vida de um aterro sanitário, foram levantadas através de pesquisa bibliográfica e documental. Dessa forma e considerando que, até o momento, o município paga pelo transbordo e pela destinação adequada de seus rejeitos no aterro sanitário de um município vizinho $(23 \mathrm{~km})$, concluiu-se que a construção de um aterro sanitário em Rancharia - SP é a alternativa mais rentável economicamente, podendo apresentar melhores retornos com a realização de financiamentos, cujas taxas são inferiores ao custo de oportunidade, bem como com a implantação de sistemas mais eficientes de coleta seletiva de materiais recicláveis.

Palavras-chave: resíduos sólidos; PNRS; análise de investimentos.

ABSTRACT - This study aimed to analyze the feasibility of building a landfill in the municipality of Rancharia - SP, aiming to meet the standards established by the National Solid Waste Policy (PNRS), reduce costs with the proper disposal of waste, reduce environmental pollution and avoid possible penalties imposed by the Environmental Company of the State of São Paulo (CETESB). A quantitative approach was carried out to verify the economic viability of investment alternatives, with the 
application of Economic Engineering methods, such as the Net Present Value (NPV) method. The information needed for the analysis, regarding the projections of solid waste generation by the municipality of Rancharia, the costs of outsourcing the proper disposal of waste, the costs of the life cycle stages of a landfill, were raised through research bibliographic and documentary. Thus, and considering that, so far, the municipality pays for the transshipment and the proper disposal of its waste at the landfill of a neighboring municipality $(23 \mathrm{~km})$, it was concluded that the construction of a landfill in Rancharia - SP is the alternative more economically profitable, being able to present better returns with the realization of financing, whose rates are lower than the opportunity cost, as well as with the implementation of more efficient systems of selective collection of recyclable materials.

Keywords: solid waste; PNRS; investimento analysis.

\section{INTRODUÇÃO}

Por ser usualmente utilizada para tratar as sobras indesejáveis de determinadas atividades, ao se fazer referência a "resíduos sólidos", remete-se à expressão coloquial da palavra lixo (BARROS, 2012). Porém, quando se leva em conta o que a normatização traz quanto ao termo, pode-se chegar a uma definição mais abrangente, principalmente por considerar seu estado (semissólido, líquido ou gasoso) e a sua procedência (doméstico, industrial, de serviços, de varrição, comercial, agrícola e hospitalar), compreendendo assim, muito mais do que a terminologia "resíduos sólidos" abrange (MUCELIN; ; BELLINI, 2008; FERREIRA, 1999; JARDIM; WELLS, 1995).

A revolução industrial ocasionou no aumento significativo de resíduos sólidos e o solo passou a ser receptáculo para o confinamento de resíduos da sociedade consumidora (RITTL et al., 2020). Embora hoje existam tecnologias extremamente sofisticadas para a destinação dos resíduos sólidos, a opção mais barata acaba sendo seu confinamento ao solo, que, por consequência, quando realizado de forma inadequada, pode acarretar em impactos ambientais como a poluição do solo, freáticos, rios, lagos ou ar (RIBEIRO, LIMA, 2000).
De modo geral, segundo Berticelli et al. (2020) os processos de tratamento de resíduos sólidos, até recentemente, não se resumiam no confinamento em aterros sanitários, sendo os resíduos sólidos dispostos em lixões (SOUZA et al., 2018; GOES, 2016). Ademais, no início do século XX, muitos países adotaram como objetivo prioritário a sustentabilidade, passando a considerar a proteção à saúde pública e aos compartimentos ambientais ar, água e solo, apenas os requisitos mínimos de processo, liderando, nas últimas duas décadas, os processos de inovação na gestão de resíduos, tanto em políticas públicas quanto nas tecnologias de tratamento.

Na França, um processo de licitação para compra de cartuchos para impressora foi vencido por uma empresa que, de 2009 a 2011, recolheu 11,5 toneladas de resíduos, economizando $30 \%$ dos custos para o governo e criando nove empregos para pessoas com deficiência física (PORTELLA; RIBEIRO, 2014).

Nos Estados Unidos (EUA), onde as autoridades gastam mais de 500 bilhões de dólares por ano em produtos e serviços, o governo federal incorporou critérios ambientais na legislação de compras. E um decreto determinou que $95 \%$ dos novos contratos usem produtos e serviços que utilizem água e energia de forma eficiente, e 
que sejam preferíveis em termos ambientais, que não usem substâncias prejudiciais à camada de ozônio e sejam produzidos em itens recicláveis (PORTELLA, RIBEIRO, 2014).

No Japão, onde $O$ governo movimentou 672 bilhões de dólares durante 2010 (17,6\% do PIB), leis para compras "verdes" exigem que ministérios, governos e um número crescente de prefeituras façam 95\% das aquisições segundo categorias definidas de "produtos verdes" (PORTELLA, RIBEIRO, 2014).

No Brasil, o contexto atual é oposto a todos esses cenários, visto que os resíduos sólidos ainda são um dos principais problemas ambientais existentes no país, principalmente pelo fato de 0 desenvolvimento socioeconômico brasileiro não ter acompanhado a implantação de empreendimentos de tratamento e de destinação de resíduos sólidos. Essa infraestrutura deficiente leva, consequentemente, ao baixo aproveitamento dos resíduos sólidos e, por conseguinte, a destinação inadequada de sua maior parcela, havendo apenas o aproveitamento através de reciclagem ou reutilização pelas atividades que trazem certo retorno econômico, como sucatas metálicas, papel, vidros e alguns plásticos.

Diante deste cenário e com o surgimento da Política Nacional de Resíduos Sólidos (PNRS), instituída pela da Lei Federal no 12.305 de 02 de agosto de 2010, estipulou-se o prazo de 4 anos para que os estados e municípios procedessem à disposição final ambientalmente adequada a seus resíduos sólidos, condicionando seu descumprimento na aplicação de sanções penais e administrativas, previstas na Lei Federal no 9.605 de 12 de fevereiro de 1998, Lei de crimes ambientais, que inclui a aplicação de multas simples, multas diárias, embargo de obras e atividades, demolição e embargo parcial ou total de atividades e condutas lesivas ao meio ambiente. Com o fim do prazo estipulado para atendimento das diretrizes da PNRS, os municípios que não conseguiram viabilizar seu cumprimento passaram a ser penalizados pelos órgãos fiscalizadores de cada estado. Tal fato levou alguns municípios a tomarem decisões urgentes para destinação adequada dos resíduos sólidos urbanos, como, por exemplo, a terceirizações dos serviços de coleta de lixo e despesas com transbordo, agravando ainda mais as dificuldades financeiras vivenciadas pelos municípios, haja vista os elevados custos para execução dos mesmos, dificultando maiores investimentos em áreas primordiais como, por exemplo, saúde e educação. Assim sendo, no município de Rancharia - SP, a solução foi contratar uma empresa que realizasse o transbordo e a destinação adequada até o aterro sanitário do município vizinho $(23 \mathrm{~km})$, Quatá - SP, pagando um determinado valor por tonelada de lixo transportado.

Diante do exposto e da escassez de recursos financeiros por parte de empresas públicas e privadas frente a inúmeras necessidades de investimentos, torna-se frequente o fato de as empresas buscarem a otimização em sua utilização. Dentre as ferramentas que contribuem para tal ocorrência, vale destacar a Engenharia Econômica que, de acordo com Ehrich (2013), apresenta-se como uma ferramenta que permite avaliar projetos de investimentos, comparando alternativas existentes ou identificadas, auxiliando o processo decisório na escolha da melhor alternativa, utilizando conceitos de microeconomia e de finanças, assim como como ferramenta de matemática financeira. Dessa forma, considerando que a solução encontrada para o município de Rancharia em relação a destinação dos resíduos sólidos urbanos acabou por onerar os cofres públicos, ressalta-se: a construção de um aterro sanitário não seria mais viável do que a terceirização do transbordo do lixo? Portanto, este estudo apresenta a hipótese de que a terceirização dos serviços de transbordo de resíduos sólidos e rejeitos para destinação ambientalmente adequada até o aterro sanitário do município vizinho foi a opção menos vantajosa economicamente. 
Como objetivo geral, procurou analisar a viabilidade da construção de um aterro sanitário no município de Rancharia SP por meio de conceitos de Engenharia Econômica. Para isso, foi estimada a quantidade média da geração de resíduos per capita do município de Rancharia - SP; levantado o curto médio por tonelada de lixo transportada até o município de Quatá - SP e; realizado a pesquisa de mercado quanto aos custos para a construção de um aterro sanitário e projetar os custos médios com as etapas do ciclo de vida do aterro sanitário.

\section{MATERIAIS E MÉTODO}

\section{1. Área de estudo}

O município de Rancharia está localizado no interior do estado de São Paulo, com uma população estimada de aproximadamente 30.000 habitantes para o ano de 2020 de acordo com o Instituto Brasileiro de Geografia e Estatística (IBGE). Atualmente o município não possui um trabalho de coleta seletiva implantada em termos de política urbana, sendo todo o lixo coletado pelo município. A equipe que coleta todo o lixo do município é composta por 1 motorista e 2 coletores.

Embora não exista um sistema de coleta seletiva implantado no município, existe uma organização de catadores de materiais recicláveis que recebe subsídio do município para auxiliar nos custos das operações e manutenção de equipamentos. Os materiais recicláveis oriundos da coleta são comercializados para o devido sustento das famílias dos 17 trabalhadores que estão em atividade. Ressalta-se que, atualmente, está sendo construído um barracão em que será instalado os equipamentos da equipe em um terreno cedido pela prefeitura do município, bem como o caminhão para a deposição dos materiais. Com exceção dos materiais recicláveis que são coletados, todo resíduo sólido do município é coletado pelo município, e, após a realização de transbordo, é destinado ao aterro sanitário do município de Quatá - SP por uma empresa terceirizada.

\subsection{Metodologia}

O desenvolvimento da investigação do problema proposto teve início com a identificação de todas as áreas envolvidas no problema proposto no caso em questão, na análise de viabilidade de construção de um aterro sanitário, nas legislações ambientais e conceitos de engenharia ambiental, orçamento público, formas de contratação do setor público e os conceitos e métodos da Engenharia Econômica.

Em relação a comparação de investimentos, considerando o tempo e o valor do dinheiro, foi utilizado a abordagem quantitativa. Já na aplicação de ferramentas de Engenharia Econômica, foram utilizados os métodos e conceitos matemáticos para comparação de investimentos, considerando a desvalorização do dinheiro ao longo do tempo e o custo de oportunidade oferecido pelo mercado.

O método utilizado de Engenharia Econômica para análise de viabilidade foi o método do Valor Presente Líquido (VPL), possibilitando a identificação da alternativa mais vantajosas do ponto de vista econômico. Dessa forma, com análise de investimentos realizada através dos métodos de Engenharia Econômica, foi possível detectar a opção mais vantajosa.

Realizou-se também, através da abordagem quantitativa, a análise das opções com a aplicação de métodos de Engenharia Econômica, de modo a detectar a opção de destinação adequada de resíduos sólidos mais viável financeiramente.

Em um segundo momento, foi feita uma pesquisa documental junto às secretarias municipais de assuntos jurídicos e de agricultura e meio ambiente da prefeitura municipal de Rancharia, com base na Lei $n$ 12.527 de 18 de novembro de 2011 que garante o acesso as informações públicas e a transparência fiscal, com o intuito de analisar todo o processo que envolve a destinação de resíduos sólidos pelo município antes e depois das sansões aplicadas pela CETESB, e obter outras informações importantes que eventualmente pudessem ter sido 
desconsideradas na identificação das áreas de estudo relacionadas ao problema. Dessa forma, de acordo com o manual de orientação para elaboração de plano simplificado de gestão integrada de resíduos sólidos, elaborado pelo Ministério de Meio Ambiente (MMA, 2016), para que se possa tomar ações necessárias de adequações para o manejo de resíduos sólidos, é necessário se estimar a geração de resíduos sólidos ano a ano, dentro do período em que se pretende realizar o planejamento. Para tanto, deve-se, primeiramente, projetar o crescimento populacional do município, pois a projeção de geração de resíduos sólidos ocorre do produto da quantidade de geração de lixo per capita pela quantidade de habitantes da localidade. Para isto, o referido manual traz métodos matemáticos e estatísticos para a projeção populacional, como o método de crescimento aritmético e o método de crescimento geométrico, usando dados históricos do IBGE para a realização dos cálculos das projeções.

Em relação à taxa de crescimento populacional, que representa o percentual de crescimento de uma população em um determinado período, a equação a seguir (Equação 1) representa a fórmula para se obter a taxa de crescimento populacional.

Equação 1: Taxa de crescimento populacional.

$$
K=\left(\frac{P 2}{P 1}\right)^{\frac{1}{t 2-t 1}}-1
$$

Fonte: Adaptado do IBGE (1991).

Sendo: $\mathrm{k}$ = taxa média de crescimento anual;

P2 = população do ano 2;

$\mathrm{P} 1=$ população do ano 1 ;

$\mathrm{t} 2=$ ano 2 ;

$\mathrm{t} 1=$ ano 1.

Com a utilização da taxa de crescimento populacional, o método geométrico chega à projeção populacional através da utilização de uma progressão geométrica, de modo que a evolução da população é representada graficamente por uma parábola. A equação a seguir (Equação
2) representa a fórmula que traduz o crescimento populacional com a aplicação do método geométrico.

Equação 2: Crescimento populacional com o método geométrico.

$$
\mathrm{P} 2=\mathrm{P} 1 \cdot(1+\mathrm{k}) \mathrm{t} 2-\mathrm{t} 1
$$

Fonte: Adaptado do Sodré (2007).

Sendo: $\mathrm{k}$ = taxa de crescimento anual médio;

P2 = população do ano 2;

P1 = população do ano $1 ;$

$\mathrm{t} 2=$ ano 2 ;

$\mathrm{t} 1=$ ano 1 .

O método aritmético consiste na soma da população atual sempre com o mesmo número de habitantes em iguais períodos. representando graficamente o crescimento populacional como uma linha reta. O cálculo pelo método aritmético é representado a seguir pela Equação 3.

Equação 3: Crescimento populacional com o método aritmético.

$$
P=P 2+\frac{P 2-P 1}{t 2-t 1} \cdot(t-t 2)
$$

Fonte: Adaptado do Sodré (2007).

Sendo: $\mathrm{P}=$ população futura do ano $\mathrm{t}$; P2 = população do último censo;

P1 = população do penúltimo censo;

t2 = ano do último censo;

t1 = ano do penúltimo censo;

$\mathrm{t}=$ ano da população futura.

Logo, considerando que, de acordo com a Associação Brasileira de Empresas de Tratamento de Resíduos (ABETRE) e pelo Ministério do Meio Ambiente (MMA), a vida útil de um aterro sanitário desde a pré implantação até o pós-encerramento é de 42 anos, e que os últimos 20 anos são destinados as etapas de encerramento e pós encerramento, tem-se que a projeção populacional, para a obtenção da projeção de resíduos sólidos, deve ser realizada pelo período de 22 anos, que é o tempo considerado pela ABETRE, pela Associação 
Brasileira de Empresas de Limpeza Pública e Resíduos Especiais (ABELPRE) e pelo MMA em que $O$ aterro sanitário estará efetivamente em operação, de modo a possibilitar a análise de viabilidade dos investimentos por períodos equivalentes (BARBOSA et al., 2020; MMA, 2020; ABELPRE; 2017;). Para tanto, conforme pesquisa realizada no banco de dados do IBGE, foi possível obter as informações referentes ao crescimento populacional do município em estudo de acordo com a Tabela 1 a seguir.

Tabela 1: Evolução populacional.

\begin{tabular}{c|c}
\hline Ano & População \\
\hline 1991 & 26.913 \\
\hline 1996 & 27.581 \\
\hline 2000 & 28.772 \\
\hline 2007 & 28.303 \\
\hline 2010 & 28.804 \\
\hline 2017 & 29.821 \\
\hline
\end{tabular}

Fonte: Adaptado do IBGE (2020).

$\mathrm{Na}$ sequência, com todas as informações obtidas, referentes a quantidade de resíduos sólidos que será gerada dentro de um determinado horizonte de tempo, realizou-se, através da Engenharia Econômica, a análise de viabilidade das alternativas existentes, com a aplicação dos métodos do Valor Presente Líquido (VPL), de modo que os fluxos de caixas obtidos serão trazidos a valor presente com o cálculo do $\mathrm{VPL}$, de modo que o projeto de investimento que apresentar maior valor de VPL será o de maior viabilidade, do ponto de vista econômico, para destinação ambientalmente adequada dos resíduos sólidos no município em estudo.

\section{RESULTADOS E DISCUSSÃO}

3.1. Projeção populacional e taxa de crescimento do município de Rancharia - SP

Com a aplicação da Equação 2 foi possível encontrar a taxa de crescimento anual da população de Rancharia nos dois últimos períodos, logo, tem-se que $\mathrm{k}=$ 0,00497 . Com a utilização da taxa de crescimento anual calculou-se, pelo período de 22 anos, o crescimento populacional do município de Rancharia com a utilização do método geométrico, descrito na Equação 3, conforme a Tabela 2.

Tabela 2. Crescimento populacional pelo método geométrico.

\begin{tabular}{c|c|c|c}
\hline Ano & Projeção & Ano & Projeção \\
\hline $\mathbf{2 0 1 8}$ & 29.969 & 2029 & 31.648 \\
\hline $\mathbf{2 0 1 9}$ & 30.117 & 2030 & 31.805 \\
\hline $\mathbf{2 0 2 0}$ & 30.267 & 2031 & 31.964 \\
\hline $\mathbf{2 0 2 1}$ & 30.418 & 2032 & 32.122 \\
\hline $\mathbf{2 0 2 2}$ & 30.569 & 2033 & 32.282 \\
\hline $\mathbf{2 0 2 3}$ & 30.721 & 2034 & 32.442 \\
\hline $\mathbf{2 0 2 4}$ & 30.873 & 2035 & 32.604 \\
\hline $\mathbf{2 0 2 5}$ & 31.027 & 2036 & 32.766 \\
\hline $\mathbf{2 0 2 6}$ & 31.181 & 2037 & 32.929 \\
\hline $\mathbf{2 0 2 7}$ & 31.336 & 2038 & 33.092 \\
\hline $\mathbf{2 0 2 8}$ & 31.492 & 2039 & 33.257 \\
\hline
\end{tabular}

Fonte: Os autores.).

Já com a projeção pelo método aritmético, descrito na Equação 3, levandose em consideração os mesmos dados extraídos do IBGE, chegou-se aos resultados constantes na Tabela 3.

Tabela 3. Crescimento populacional para o método geométrico.

\begin{tabular}{c|c|c|c}
\hline Ano & Projeção & Ano & Projeção \\
\hline $\mathbf{2 0 1 8}$ & 29.966 & 2029 & 31.564 \\
\hline $\mathbf{2 0 1 9}$ & 30.111 & 2030 & 31.709 \\
\hline $\mathbf{2 0 2 0}$ & 30.256 & 2031 & 31.855 \\
\hline $\mathbf{2 0 2 1}$ & 30.402 & 2032 & 32.000 \\
\hline $\mathbf{2 0 2 2}$ & 30.547 & 2033 & 32.145 \\
\hline $\mathbf{2 0 2 3}$ & 30.692 & 2034 & 32.290 \\
\hline $\mathbf{2 0 2 4}$ & 30.838 & 2035 & 32.436 \\
\hline $\mathbf{2 0 2 5}$ & 30.983 & 2036 & 32.581 \\
\hline $\mathbf{2 0 2 6}$ & 31.128 & 2037 & 32.726 \\
\hline $\mathbf{2 0 2 7}$ & 31.273 & 2038 & 32.872 \\
\hline $\mathbf{2 0 2 8}$ & 31.418 & 2039 & 33.017 \\
\hline
\end{tabular}

Fonte: Os autores.

Assim sendo, adotou-se a estimativa que mais se adequou ao histórico de crescimento do município. Contudo, ressaltase que a dinâmica do comportamento do crescimento populacional pode apresentar 
comportamento dinâmico, considerando que pode sofrer alterações significativas, como, por exemplo, a instalação de empreendimentos e novas indústrias que possam, diretamente ou indiretamente, influenciar o crescimento e desenvolvimento populacional. Em contrapartida, o município de Rancharia apresentou, para ambos os métodos, valores bem semelhantes, possibilitando a escolha de qualquer uma das estimativas obtidas, de modo que haverá pouca influência no resultado da projeção da geração de resíduos sólidos pela grande semelhança dos dados obtidos. Neste contexto, adotou-se os valores obtidos através da aplicação do Método Aritmético, para que se possa estimar a quantidade de resíduos sólidos urbanos que será gerada no futuro, levando se em conta a estimativa populacional e a estimativa de geração de resíduos sólidos per capita.

\subsection{Estimativa da geração de resíduos sólidos}

Para a estimativa de geração de resíduos sólidos no município, considerou-se o produto da população estimada e a média de geração de resíduos sólidos urbanos per capita da população ranchariense nos últimos anos. Diante deste contexto, com as informações coletadas junto à Secretaria Municipal de Agricultura e Meio Ambiente de Rancharia (SEMAM), foi possível obter informações relativas à quantidade de resíduos sólidos urbanos transportadas pela empresa Monte Azul Engenharia LTDA em alguns meses de suas operações no município, conforme Tabela 4. Ressalta-se que os dados a seguir estão desconsiderando os materiais recicláveis coletados pela Associação dos Catadores de Materiais Recicláveis de Rancharia (UNIVENCE), o que reduz a quantidade de resíduos a serem destinados ao aterro sanitário do município de Quatá - SP e, consequentemente, custos.
Tabela 4. Histórico da geração de resíduos do município em tonelada/mês.

\begin{tabular}{c|c|c|c|c}
\hline & $\mathbf{2 0 1 4}$ & $\mathbf{2 0 1 5}$ & $\mathbf{2 0 1 6}$ & $\mathbf{2 0 1 7}$ \\
\hline Jan. & - & 630,8 & 588,1 & - \\
& & 5 & 7 & \\
\hline Fev. & - & 542,4 & 540,5 & - \\
& & 1 & 1 & \\
\hline Mar. & - & 511,7 & 598,5 & 486,2 \\
& & 2 & 4 & 5 \\
\hline Abr. & - & 540,4 & 506,4 & 443,3 \\
& & 6 & 8 & 8 \\
\hline Mai & - & 478,7 & - & - \\
o & & 5 & & \\
\hline Jun. & - & 618,9 & - & 479,8 \\
& & 8 & & 5 \\
\hline Jul. & 492,4 & 519,7 & 496,1 & 505,3 \\
& 5 & 4 & 0 & 3 \\
\hline Ago. & 487,6 & - & 545,2 & - \\
& 6 & & 1 & \\
\hline Set. & 604,7 & 541,9 & 502,3 & - \\
& 4 & 6 & 6 & \\
\hline Out. & 605,9 & 571,6 & - & - \\
& 4 & 3 & & \\
\hline Nov. & 554,9 & 534,9 & - & - \\
& 0 & 6 & & \\
\hline Dez. & 606,9 & 556,5 & - & - \\
& 5 & 9 & & \\
\hline & & &
\end{tabular}

Fonte: Os autores.

Ressalta-se que não foi possível obter todas as informações referentes à geração de resíduos sólidos no município desde o início (2014) da operação da empresa Monte Azul Engenharia LTDA, devido ao fato da substituição da gestão do município que ocasionou na perca de algumas informações. Porém, através das informações obtidas, foi possível chegar a uma geração média per capita por mês através da utilização do Método Aritmético, conforme verificado na Tabela 5. 
Tabela 5. Geração média per capita de resíduos sólidos.

\begin{tabular}{c|c|c|c}
\hline & $\begin{array}{c}\text { Média } \\
\text { resíduos } \\
\text { sólidos } \\
\text { (Ton./mê } \\
\text { s) }\end{array}$ & $\begin{array}{c}\text { Populaç } \\
\text { ão }\end{array}$ & $\begin{array}{c}\text { Resíduos } \\
\text { sólidos } \\
\text { per } \\
\text { capita } \\
\text { (Kg/dia) }\end{array}$ \\
\hline $\mathbf{2 0 1 4}$ & 558,77 & 29.386 & 0,634 \\
\hline $\mathbf{2 0 1 5}$ & 549,82 & 29.531 & 0,621 \\
\hline $\mathbf{2 0 1 6}$ & 539,62 & 29.676 & 0,606 \\
\hline $\mathbf{2 0 1 7}$ & 478,70 & 29.821 & 0,535 \\
\hline $\begin{array}{c}\text { Médi } \\
\text { a }\end{array}$ & 531,73 & 29.603 & 0,599 \\
\hline
\end{tabular}

Fonte: Os autores.

Após a obtenção da quantidade de geração média de resíduos sólidos per capita/dia foi possível projetar a geração de resíduos sólidos para o horizonte de tempo pretendido, partindo do pressuposto que o comportamento de geração de resíduos permaneça de maneira estável e não apresente crescimentos significativos. Deste modo, com a projeção populacional obtida e as informações anteriores, foram obtidos os dados apresentados na Tabela 6. Ressalta-se que todos os anos para a geração per capita de resíduos sólidos obtiveram o mesmo valor $(0,599 \mathrm{~kg} / \mathrm{dia})$.
Tabela 6. Projeção da geração de resíduos sólidos.

\begin{tabular}{l|c|c|c}
\hline & \multicolumn{3}{|c}{ Geração de resíduos (Toneladas) } \\
\hline Ano & $\begin{array}{c}\text { Geração } \\
\text { diária }\end{array}$ & $\begin{array}{c}\text { Geração } \\
\text { mensal }\end{array}$ & $\begin{array}{c}\text { Geração } \\
\text { anual }\end{array}$ \\
\hline $\mathbf{2 0 1 8}$ & 17,95 & 538,49 & $6.461,87$ \\
\hline $\mathbf{2 0 1 9}$ & 18,04 & 541,09 & $5.493,14$ \\
\hline $\mathbf{2 0 2 0}$ & 18,12 & 543,70 & $6.524,40$ \\
\hline $\mathbf{2 0 2 1}$ & 18,21 & 546,32 & $5.555,89$ \\
\hline $\mathbf{2 0 2 2}$ & 18,30 & 548,93 & $6.587,16$ \\
\hline $\mathbf{2 0 2 3}$ & 18,38 & 551,54 & $6.618,42$ \\
\hline $\mathbf{2 0 2 4}$ & 18,47 & 554,16 & $6.649,91$ \\
\hline $\mathbf{2 0 2 5}$ & 18,56 & 556,76 & $6.681,17$ \\
\hline $\mathbf{2 0 2 6}$ & 18,65 & 559,37 & $6.712,44$ \\
\hline $\mathbf{2 0 2 7}$ & 18,73 & 561,98 & $6.743,71$ \\
\hline $\mathbf{2 0 2 8}$ & 18,82 & 564,60 & $6.775,19$ \\
\hline $\mathbf{2 0 2 9}$ & 18,91 & 567,21 & $6.806,46$ \\
\hline $\mathbf{2 0 3 0}$ & 18,99 & 569,81 & $6.837,73$ \\
\hline $\mathbf{2 0 3 1}$ & 19,08 & 572,43 & $6.869,21$ \\
\hline $\mathbf{2 0 3 2}$ & 19,17 & 575,04 & $6.900,48$ \\
\hline $\mathbf{2 0 3 3}$ & 19,25 & 577,65 & $6.931,75$ \\
\hline $\mathbf{2 0 3 4}$ & 19,34 & 580,25 & $6.963,02$ \\
\hline $\mathbf{2 0 3 5}$ & 19,43 & 582,87 & $6.994,50$ \\
\hline $\mathbf{2 0 3 6}$ & 19,52 & 585,48 & $7.025,77$ \\
\hline $\mathbf{2 0 3 7}$ & 19,60 & 588,09 & $7.057,03$ \\
\hline $\mathbf{2 0 3 8}$ & 19,69 & 590,71 & $7.088,52$ \\
\hline $\mathbf{2 0 3 9}$ & 19,78 & 593,32 & $7.119,79$ \\
\hline $\mathbf{2 0 n}: 05$ & & \\
\hline
\end{tabular}

Fonte: Os autores.

Diante da estimativa de geração de resíduos sólidos no horizonte de tempo equivalente as etapas que o aterro sanitário permanece em operação, foi possível realizar a análise de viabilidade de investimentos, dentro do período determinado, uma vez que ambos contarão com fluxos de caixas distintos, onde é possível identificar a alternativa mais viável do ponto de vista econômico.

\subsection{Análise econômica dos custos com a terceirização}

Quanto aos custos que atualmente ocorrem com a destinação do lixo até o aterro sanitário de Quatá, após a coleta de informações junto a Prefeitura municipal de Rancharia, constatou-se que os valores cobrados incluem o transbordo, transporte e a taxa cobrada pelo aterro sanitário de 
Quatá para armazenar os resíduos sólidos. Diante dos fatos, não foi possível realizar a distinção dos custos relacionados ao transbordo, do transporte, e dos custos relacionados ao recebimento dos resíduos pelo aterro sanitário do município de Quatá. Outro fator considerado na coleta de dados foi o de que, anualmente, existe reajuste de preços com a terceirização, conforme apresentado na Tabela 7.

Tabela 7. Valores da terceirização da disposição final dos resíduos.

\begin{tabular}{c|c|c}
\hline Ano & $\begin{array}{c}\text { Valor } \\
\text { (R\$/Tonelada) }\end{array}$ & $\begin{array}{c}\text { Reajuste } \\
\text { (\%) }\end{array}$ \\
\hline $\mathbf{2 0 1 4}$ & 154,00 & - \\
\hline $\mathbf{2 0 1 5}$ & 166,96 & $8,41 \%$ \\
\hline $\mathbf{2 0 1 6}$ & 183,50 & $9,91 \%$ \\
\hline $\mathbf{2 0 1 7}$ & 173,50 & $-5,45 \%$ \\
\hline Média & 169,49 & $4,29 \%$ \\
\hline
\end{tabular}

Fonte: Os autores.

Em relação a projeção dos valores que serão despendidos ao longo do ciclo de vida de um aterro sanitário com a manutenção da terceirização dos serviços de disposição final dos resíduos sólidos, utilizou-se a média do índice inflacionário, de modo a garantir a atualização monetária no período. Dessa forma, utilizou-se a variação histórica do Índice Nacional de Preços ao Consumidor Amplo (IPCA), obtidos no IBGE, conforme a Tabela 8.

Tabela 8. Variação do IPCA dos últimos 10 anos.

\begin{tabular}{c|c}
\hline Ano & Variação no ano (\%) \\
\hline $\mathbf{2 0 0 7}$ & 4,46 \\
\hline $\mathbf{2 0 0 8}$ & 5,90 \\
\hline $\mathbf{2 0 0 9}$ & 4,31 \\
\hline $\mathbf{2 0 1 0}$ & 5,91 \\
\hline $\mathbf{2 0 1 1}$ & 6,50 \\
\hline $\mathbf{2 0 1 2}$ & 5,84 \\
\hline $\mathbf{2 0 1 3}$ & 5,91 \\
\hline $\mathbf{2 0 1 4}$ & 6,41 \\
\hline $\mathbf{2 0 1 5}$ & 10,67 \\
\hline $\mathbf{2 0 1 6}$ & 6,29 \\
\hline Média & 6,22 \\
\hline
\end{tabular}

Fonte: Os autores.
Logo, com a adoção de uma taxa média de reajuste de $6,22 \%$, pode-se obter, a partir da projeção da geração de resíduos sólidos, os valores que serão despendidos com a prestação de serviços de transbordo, transporte e destinação ambientalmente adequada até o município de Quatá, conforme a Tabela 9.

Tabela 9. Projeção dos valores oriundos do serviço terceirizado.

\begin{tabular}{l|l|l|l}
\hline Ano & $\begin{array}{l}\text { Valor } \\
\text { (R\$/Ton) }\end{array}$ & $\begin{array}{l}\text { Taxa de } \\
\text { reajuste } \\
\text { médio } \\
\text { anual } \\
\text { (\%) }\end{array}$ & $\begin{array}{l}\text { Valor atual } \\
\text { (R\$) }\end{array}$ \\
\hline $\mathbf{2 0 1 8}$ & 184,29 & 6,22 & $1.190 .858,02$ \\
\hline $\mathbf{2 0 1 9}$ & 195,75 & 6,22 & $1.271 .032,16$ \\
\hline $\mathbf{2 0 2 0}$ & 207,93 & 6,22 & $1.356 .618,49$ \\
\hline $\mathbf{2 0 2 1}$ & 220,86 & 6,22 & $1.447 .933,87$ \\
\hline $\mathbf{2 0 2 2}$ & 234,60 & 6,22 & $1.545 .347,74$ \\
\hline $\mathbf{2 0 2 3}$ & 249,19 & 6,22 & $1.649 .244,08$ \\
\hline $\mathbf{2 0 2 4}$ & 264,69 & 6,22 & $1.760 .164,68$ \\
\hline $\mathbf{2 0 2 5}$ & 281,16 & 6,22 & $1.878 .477,76$ \\
\hline $\mathbf{2 0 2 6}$ & 298,65 & 6,22 & $2.004 .670,21$ \\
\hline $\mathbf{2 0 2 7}$ & 317,22 & 6,22 & $2.139 .239,69$ \\
\hline $\mathbf{2 0 2 8}$ & 336,95 & 6,22 & $2.282 .900,27$ \\
\hline $\mathbf{2 0 2 9}$ & 357,91 & 6,22 & $2.436 .100,10$ \\
\hline $\mathbf{2 0 3 0}$ & 380,17 & 6,22 & $2.599 .499,81$ \\
\hline $\mathbf{2 0 3 1}$ & 403,82 & 6,22 & $2.773 .924,38$ \\
\hline $\mathbf{2 0 3 2}$ & 428,94 & 6,22 & $2.959 .891,89$ \\
\hline $\mathbf{2 0 3 3}$ & 455,62 & 6,22 & $3.158 .243,94$ \\
\hline $\mathbf{2 0 3 4}$ & 483,96 & 6,22 & $3.369 .823,16$ \\
\hline $\mathbf{2 0 3 5}$ & 514,06 & 6,22 & $3.595 .592,67$ \\
\hline $\mathbf{2 0 3 6}$ & 546,03 & 6,22 & $3.836 .281,19$ \\
\hline $\mathbf{2 0 3 7}$ & 580,00 & 6,22 & $4.093 .077,40$ \\
\hline $\mathbf{2 0 3 8}$ & 616,07 & 6,22 & $4.367 .024,52$ \\
\hline $\mathbf{2 0 3 9}$ & 654,39 & 6,22 & $4.659 .119,38$ \\
\hline Fonte: & & & \\
\hline
\end{tabular}

Com a projeção dos valores que serão gastos pelo município de Rancharia ao longo do período de 22 anos foi possível obter os fluxos de caixa anuais do referido investimento. Estas informações se deram a partir das projeções populacionais, geração per capita média de resíduos sólidos no 
município de Rancharia, projeção de geração de resíduos sólidos, e a projeção dos valores atualmente cobrados por tonelada de resíduo sólido, com uma taxa média de inflação de $6,22 \%$. Assim sendo, a partir dos fluxos de caixa da terceirização obtidos, chegou-se ao VPL do investimento, o que possibilitou a comparação com o VPL do investimento na construção do aterro sanitário, também a partir dos fluxos de caixa do referido empreendimento.

Após aplicar o método do VPL, descrito na Equação 1, utilizando-se como custo de oportunidade a taxa referencial do Sistema Especial de Liquidação e de Custódia (Selic) acumulada nos últimos 12 meses que totalizou $11,46 \%$, pode-se obter um VPL = 15.899.672,08.

\subsection{Análise econômica dos custos do aterro sanitário}

De acordo com a ABETRE (2007), existem três portes de aterros sanitários: pequeno, médio e grande, com as respectivas capacidades diárias: 100, 800 e 2.000 toneladas. Neste contexto, um aterro sanitário de pequeno porte para o município de Rancharia seria o essencial, considerando que, atualmente, a geração diária do município se aproxima de 18 toneladas/dia. Neste caso, com o aterro sanitário de pequeno porte, existiria uma capacidade ociosa diária de mais de $80 \%$, o que possibilitaria o recebimento de resíduos sólidos de outros municípios, que, por sua vez, efetuariam pagamento por tonelada de resíduo sólido recebido. Além disso, para o desenvolvimento da presente análise, foram considerados os custos de construção disponibilizados pela ABETRE (2007), porém, atualizados de acordo com o IPCA até o ano de 2016, e a partir deste ano utilizada a projeção do índice no horizonte de tempo utilizado. Desse modo, chegou-se aos custos das etapas de viabilização de um aterro sanitário de pequeno porte, conforme a Tabela 10.
Tabela 10. Custo de viabilização de aterro de pequeno porte.

\begin{tabular}{l|l|l}
\hline Etapa & $\begin{array}{l}\text { Participaçã } \\
\text { o sobre o } \\
\text { total (\%) }\end{array}$ & $\begin{array}{l}\text { Custo da } \\
\text { etapa (R\$) }\end{array}$ \\
\hline $\begin{array}{l}\text { Pré- } \\
\text { Implantação }\end{array}$ & 1,16 & $1.110 .494,71$ \\
\hline Implantação & 5,09 & $4.874 .472,20$ \\
\hline Operação & 86,70 & $\begin{array}{l}83.034 .287,0 \\
1\end{array}$ \\
\hline $\begin{array}{l}\text { Encerrament } \\
\text { o }\end{array}$ & 0,93 & $888.754,80$ \\
\hline $\begin{array}{l}\text { Pós } \\
\text { Encerrament } \\
\text { o }\end{array}$ & 6,13 & $5.866 .424,17$ \\
\hline Custo total & 100 & $\begin{array}{l}95.774 .432,8 \\
9\end{array}$ \\
\hline \multicolumn{2}{l}{ Fonte: Adaptado de ABETRE (2007). } \\
\hline
\end{tabular}

Ressalta-se que as etapas de operação e de pós-encerramento apresentam discrepância ante as demais pelo fato de os valores investidos serem despendidos ao longo de 20 anos de operação e de 20 anos de pósencerramento. Além disso, a etapa de implantação também apresenta valores significativamente mais elevados que as etapas de pré-implantação e de encerramento, devido ao fato de incluir a construção de toda estrutura do aterro sanitário. Sendo assim, a distribuição percentual dos valores de cada etapa de viabilização do aterro ocorre de acordo com a Tabela 11. 
Tabela 11. Distribuição percentual dos custos de viabilização.

\begin{tabular}{|c|c|c|c|c|c|}
\hline Etapa & 1 & 2 & $\begin{array}{l}3 \\
2 \\
2\end{array}$ & 23 & $\begin{array}{l}2 \\
3 \\
- \\
4 \\
2\end{array}$ \\
\hline $\begin{array}{l}\text { Pré- } \\
\text { Implantaçã } \\
0\end{array}$ & $\begin{array}{l}100 \\
\%\end{array}$ & & & & \\
\hline $\begin{array}{l}\text { Implantaçã } \\
\text { o }\end{array}$ & & $\begin{array}{l}100 \\
\% \\
\end{array}$ & & & \\
\hline Operação & & & $\begin{array}{l}5 \\
\%\end{array}$ & & \\
\hline $\begin{array}{l}\text { Encerrame } \\
\text { nto }\end{array}$ & & & & $\begin{array}{l}100 \\
\% \\
\end{array}$ & \\
\hline $\begin{array}{l}\text { Pós } \\
\text { encerrame } \\
\text { nto }\end{array}$ & & & & $5 \%$ & $\begin{array}{l}5 \\
\%\end{array}$ \\
\hline
\end{tabular}

Fonte: ABETRE (2007).

A partir destes valores foi possível obter o fluxo de caixa do empreendimento ao longo de seu ciclo de vida. Além disso, pode-se obter o custo médio por tonelada de resíduos sólido recebido, conforme observado na Tabela 12.

Tabela 12. Custo médio por tonelada de resíduo sólido.

\begin{tabular}{l|l|l}
\hline & Tonelada & Custo (R\$) \\
\hline $\begin{array}{l}\text { Capacidade } \\
\text { total }\end{array}$ & 730.000 & $95.774 .432,89$ \\
\hline Média & 01 & 131,19 \\
\hline
\end{tabular}

Fonte: Adaptado de ABETRE (2007).

Com a detecção do custo médio por tonelada de resíduo sólido, o município de Rancharia pode receber resíduos sólidos de outros municípios da região, considerando a capacidade ociosa média do aterro sanitário ao longo de seu ciclo de vida, que será aproximadamente de $80 \%$. Outro aspecto importante considerado foi a atualização monetária dos valores despendidos ao longo do investimento, bem como o custo por tonelada de resíduo sólido, ambos considerando a taxa média do IPCA de 6,22\%. Neste contexto, vale mencionar que $o$ período de análise é de 22 anos, porém o VPL do investimento do aterro sanitário levará em conta, também, o período de pósencerramento, onde haverá saídas de caixa para o monitoramento do aterro sanitário, sem que o mesmo possa receber resíduos sólidos. Logo, com a obtenção dos valores do fluxo de caixa operacional do aterro sanitário, conforme apresentado a seguir, foi possível calcular o VPL do aterro sanitário, obtendo-se um VPL= -12.996.698,27.

Dessa forma percebe-se que, embora o aterro sanitário possua a etapa de pós encerramento, onde existe apenas saídas de caixa, o investimento ainda é mais vantajoso economicamente do que a terceirização para destinação adequada dos resíduos sólidos no município de Quatá-SP, que apresentou um VPL=- 15.899.672,08. Porém, embora o investimento na construção de um aterro sanitário já apresente um VPL maior do que o da terceirização, é possível se obter ainda, para a execução do projeto, linhas de financiamento cujo as taxas de juros são menores do que as de custo de oportunidade, que no caso em questão é a taxa Selic de $11,46 \%$. Para tanto foi utilizada a linha de financiamento do BNDES para o Desenvolvimento Integrado dos Municípios (FINEM), com Taxa de Juros de Longo Prazo (TJLP) de 9,7. Com a inclusão do financiamento no fluxo de caixa operacional, com a dedução do Imposto de Renda sobre os juros incidentes nas parcelas do financiamento, foi possível chegar ao fluxo de caixa do acionista. Isto permitiu que o investimento pudesse obter alavancagem financeira, de modo que o fluxo de caixa do acionista é mais rentável que o fluxo de caixa operacional, podendo tornar o investimento mais rentável. Após o cálculo do VPL do fluxo de caixa do acionista, foi possível encontrar um VPL $=10.811 .536,68$. Desse modo, observa-se que o projeto do aterro sanitário além de ser mais vantajoso economicamente ante a terceirização, apresenta VPL positivo ante ao custo de oportunidade de $11,46 \%$, podendo ser ainda maior, caso exista 
margem de lucro sobre o valor cobrado por tonelada de resíduo.

Os resultados apresentados na presente pesquisa corroboram aos estudos correlatos (GULARTE et al., 2020; ULCHAK et al., 2020; VISENTIN et al., 2020), em que os autores verificaram a viabilidade $d a$ construção da implantação local de uma usina de tratamento e/ou aterro sanitário do que o pagamento para transbordo.

\section{CONSIDERAÇÕES FINAIS}

Por meio do VPL de ambos os projetos foi possível identificar que a construção de um aterro sanitário no município de Rancharia - SP é mais vantajosa do ponto de vista econômica do que o cenário atual de terceirização. Embora ambos VPL'S apresentaram valor negativo, este contexto é alterado quando calculado o VPL do aterro sanitário a partir do fluxo de caixa do acionista, com a realização de financiamento através do BNDES, cujas TJLP possibilitam a alavancagem financeira por serem menores que as taxas de custo de oportunidade, utilizada taxa Selic, de modo que o VPL passou a ser positivo. Ademais, ressalta-se que a construção de um aterro sanitário no município, junto à PNRS, poderá influenciar diretamente na implantação de um sistema de colega seletiva eficiente e eficaz.

Convém ressaltar que os resultados apresentados são representados pelo cenário atual do município analisado e que, alterações da legislação em âmbito estadual e federal podem alterá-los.

Por fim, é digno frisar que a construção de um aterro sanitário perante ao cenário atual do município de Rancharia - SP acarretaria na geração de emprego e renda. Além disso, é válido destacar, em qualquer caso, a necessidade de eliminar os lixões, com vista ao aproveitamento energético dos resíduos e de se dispor de informações sobre a composição desses. Além disso, a energia proveniente desses locais ocasiona, diretamente, na conservação dos recursos naturais.

\section{REFERÊNCIAS}

BERTICELLI, R.; DECESARO, A.; PANDOLFO, A.; PASQUALI, P. B. Contribuição da coleta seletiva para o desenvolvimento sustentável municipal. Revista em Agronegócios e Meio Ambiente, v. 13, n.2), p. 2020. https://doi.org/10.17765/21769168.2020v13n2p781-796

BETRE. ASSOCIAÇÃO BRASILEIRA DE EMPRESAS DE TRATAMENTO DE RESÍDUOS Estudo sobre os aspectos econômicos e financeiros da implantação e operação de aterros sanitários. São Paulo: BETRE, 2007.

BARROS, R. M. Tratado sobre Resíduos Sólidos: Gestão, Uso e Sustentabilidade. Rio de Janeiro: Acta Interciência, 2012.

BRASIL. Lei no 12.305, de 02 de agosto de 2010. Que institui a Política Nacional dos Resíduos Sólidos, e dá outras providências. Diário Oficial da União, Brasília, DF, 22 nov. 2010.

BRASIL. Lei no 9.605, de 12 de fevereiro de 1998. Que dispõe sobre as sanções penais e administrativas derivadas de condutas e atividades lesivas ao meio ambiente, e dá outras providências. Diário Oficial da União, Brasília, DF, 13 mar. 1998.

IBGE., Censo demográfico. Rio de Janeiro: IBGE, 1991.

EHRLICH, P. J.; MORAIS, E. A. Engenharia econômica: avaliação e seleção de projetos de investimento. São Paulo: Atlas, 2005.

FERREIRA, A. B. de H. Dicionário Aurélio eletrônico século XXI. Rio de Janeiro: Nova Fronteira, 1999. 1 CD-ROM.

GOES, D. A contribuição do aterro sanitário de resíduos sólidos - um breve estudo de caso no aterro de Paulo Afonso, BA. Revista Científica da FASETE, v. 1, p. 90-105, 2016. 
GULARTE, L.C.P., LIMA, J.D.D., OLIVEIRA, G.A., BARICHELLO, R.; PINTO, M.A.N. Modelo de avaliação da viabilidade econômicofinanceira da implantação de usinas de reciclagem de resíduos da construção civil em municípios brasileiros. Engenharia Sanitaria e Ambiental, v. 25, n. 2, p.281-291, 2020. https://doi.org/10.1590/s1413-

$\underline{41522020193153}$

IBGE. INSTITUTO BRASILEIRO DE GEOGRAFIA E eSTATísticA. Censo Populacional. Rio de Janeiro: IBGE, 2010.

JARDIM, N. S.; WELLS, C. (org.). Lixo Municipal: Manual de Gerenciamento integrado. São Paulo: IPT: CEMPRE, 1995.

BRASIL. Ministério do Meio Ambiente (MMA) -Coleta Seletiva. Brasília: MMA, 2016. Disponível em: http://www.mma.gov.br/cidadessustentaveis/residuos-solidos/catadores-demateriais-reciclaveis/reciclagem-ereaproveitamento. Brasilia: MMA, 2016.

MUCELIN, C. A.; BELLINI, M. Lixo e impactos ambientais perceptíveis no ecossistema urbano. Sociedade \& natureza, v. 20, n. 1 , p.111-124. 2008.

https://doi.org/10.1590/S1982-

$\underline{45132008000100008}$

PORTELLA, M. O.; RIBEIRO, J. C. J. Aterros sanitários: aspectos gerais e destino final dos resíduos. Revista Direito Ambiental e Sociedade, v. 4, n. 1, 2014.

RIBEIRO, T. F.; DO CARMO LIMA, S.. Coleta seletiva de lixo domiciliar-estudo de casos. Caminhos de geografia, v. 2, n. 2, 2001.

RITTL, L. G. F.; PINCELLI, I. P.; RUTKOWSKI, E.W.; MOREIRA, G. A.; DE MEDEIROS, M. G.; CARDOSO, M. G.; DE CAMPOS, T. M. P.; ANTUNES, M. C.; VIEIRA, B.; DE CASTILHOS JUNIOR, A.B. Avaliação da implementação da rede internacional de cooperação acadêmica lixo zero (nizac) no Brasil. Revista Gestão \&
Sustentabilidade Ambiental, v.9, n.1 (esp), p.269-287, 2020. https://doi.org/10.19177/rgsa.v9e02020269$\underline{287}$

SODRÉ, U. Crescimento populacional. Matemática, UEL. Londrina: UEL, 2007.

SOUZA, L. S.; ANDRADE, G. G.; MORAES, G. R. Um lixão sob o ponto de vista da geofísica rasa, município de Caracaraí, Roraima, Brasil. Revista de Geociências do Nordeste, v. 4, n. 1, p.21-41. 2018

ULCHAK, N. C., DOMICIANO, A. K., VIECHNEISKI, G. R., UEHARA, S. C. D. S. A.; VEIGA, T. B. Avaliação da disposição dos Resíduos Sólidos Urbanos de Rebouças em Aterro Sanitário. Gestão de Resíduos Sólidos, v. p.3 8. 2020. https://doi.org/10.36229/97885-7042-219-4.CAP.07

VISENTIN, R.; MATEUS, C.; ESPERANCINI, M; BOAS, R. V. Viabilidade econômica da compostagem do lodo de esgoto para uso agrícola. Holos Environment, v. 20, n. 2, p.152-167, 2020. https://doi.org/10.14295/holos.v20i2.12372 